\section{The Old and the New}

Happy New Year! Just like many other places, the Materials Research Society is ringing in the new. Among other things, this means ringing in a new President. And if there is someone new in her job at MRS, it is me. To make the point: the MRS Executive Director has been at his job for 24 years (more about this later); our other 37 staff members average around eight years each at MRS; our volunteer committee chairs are officially signed on for three years although they often stay longer; and even our Board members serve for three years. Although there is a warm-up year as vice president (Shefford P. Baker from Cornell University is now in the batting box) and a cooldown year as past president (2007 President Alan J. Hurd from Los Alamos National Laboratory is still going at full power), the presidential term is only one year. And so I will do my best to get it right the first time.

But enough of my long years of experience and eminent qualifications for the job. You may also be new to your job as an MRS member. That you are now reading the MRS Bulletin means you are a member (unless you picked this copy up off a bus seat or borrowed it from a colleague) and I hope you consider yourself in good company. It is certainly an abundance of company, since our total membership reached close to 15,000 for the first time last year. As a group, we come from academia (54\%), government $(18 \%)$, and industry (24\%); we come from the United States (64\%), Europe (11\%), Asia $(12 \%)$, and other places $(13 \%)$. To a large extent, our topical interests mirror the technical areas of the two annual meetings since $55 \%$ of us become members by attending these meetings. And since our meetings have unerringly tracked the moving frontier of cutting-edge materials research, so also do we.

The roaring success of the two annual meetings (Boston in November and San Francisco in April) is largely attributed to

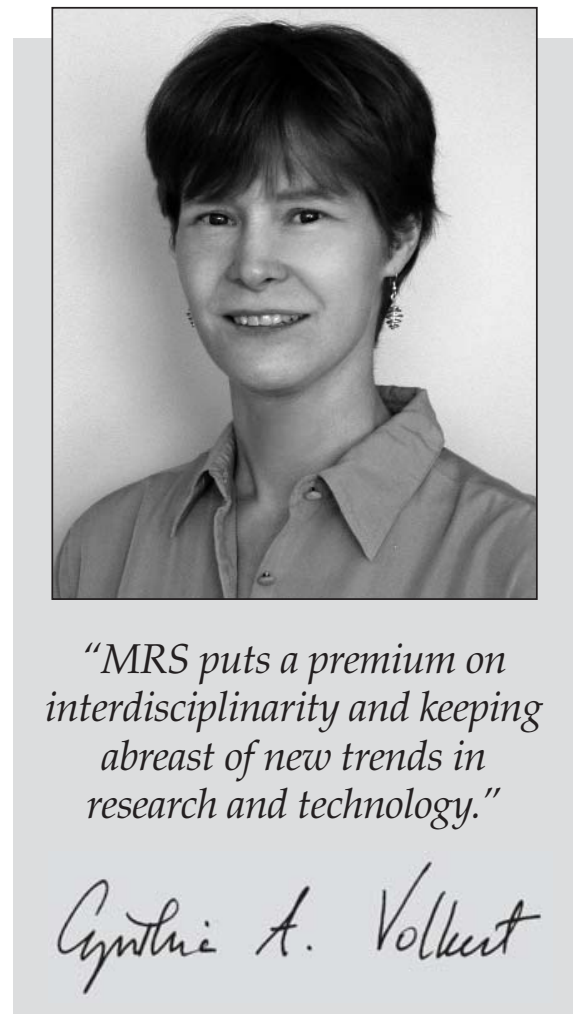

the meeting chairs, who select 40-odd technical topics from the evolving landscape of materials research that they believe will have the most scientific impact. Anyone watching the process is filled with trepidation. But time and again, MRS reinvents itself and pulls off worldleading materials research conferences.

In many ways, MRS is like a herd of cats that can dart in any direction and always land on its feet. But nonetheless, we have slowly and surely been growing to a society with more scope and impact, to a society that provides its members and the materials research community with broad opportunities to do outstanding research. We have had a successful, longterm commitment to including biological materials and soft matter research into the society, and more recently, have made commitments to furthering materials research for energy and the environment and to advocacy. But we have further to go to engage the best and brightest of materials research. MRS puts a premium on interdisciplinarity and keeping abreast of new trends in research and technology. This has meant that in-depth and fundamental research-yesterday's cutting edge, if you will forgive the expressionare often neglected. Keeping these communities in MRS will give us depth and staying power. But we should also be looking to grow in scope and impact by finding additional communities who would benefit from interactions with us. Materials research is a global enterprise: the problems are global and the funding and the people are as well. I hope that we will take this next step by building bridges, through collaboration and alliances with other organizations and societies. We have already started, with our jointly organized International Materials Research Conference to be held in Chongqing in June of this year.

We are well-positioned for these changes, but the challenges are not insignificant. In addition to everything else, the MRS Executive Director, John B.

Ballance, will retire this year and his successor is being sought. Ballance runs the MRS Headquarters and is the keeper of institutional memory and experience. He has provided ballast for 24 presidents and kept us on course. Whatever the style of his successor, it is crucial that it further allow the steady, expert, and thoughtful support from MRS Headquarters.

So MRS will not only be ringing in the new, we will be ringing out the old. And, of course, we will be handling the ludicrous job of steering a cart pulled by a herd of cats.

CYNTHIA A. VOLKERT 2008 MRS President

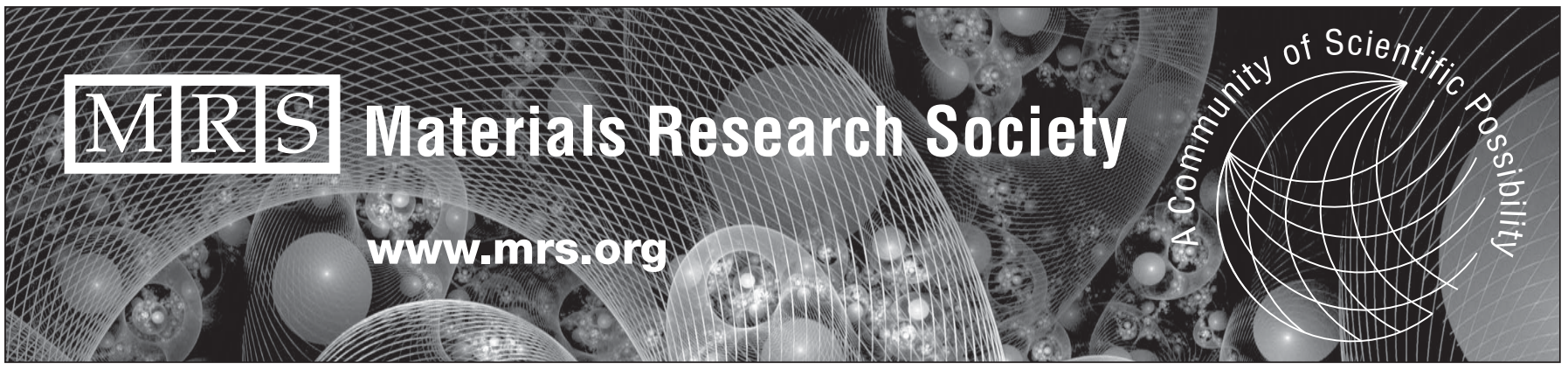

